\title{
USANDO OS RECURSOS DA INTERNET NA ENFERMAGEM
}

Maria Helena Larcher Caliri*

\section{INTRODUÇÃO}

A Internet, que iniciou-se como um projeto militar de defesa americana no final da década de 60 , hoje é a maior rede de informações do mundo, usada por agências governamentais, universidades, empresas e por qualquer pessoa que se interesse em ter acesso ao conhecimento divulgado. $\mathrm{O}$ acesso à informação disponível na Internet possibilita uma socialização do conhecimento em todas as áreas de interesse, porém, a maior parte das informações na língua inglesa o que exige do usuário conhecimentos básicos para melhor aproveitamento.

O conceito de tempo e espaço foi profundamente modificado pela Internet e através da rede podemos estar ligados aos grandes centros de pesquisa, às grandes bibliotecas e interagir com colegas da profissão em todas as partes do país e do mundo de maneira eficiente. Este importante avanço da comunicação tem muito a oferecer na área de enfermagem; no entanto, as possibilidades reais de estabelecimento de novos elos, oferecimento e uso de serviços, depende do nosso esforço e aceitação do "novo" para que as interações ocorram efetivamente. $\mathrm{O}$ objetivo deste artigo é divulgar alguns instrumentos da Internet que são úteis na prática profissional do enfermeiro e formas de utilizá-los.

\section{COMPONENTES DA INTERNET}

\section{Correio eletrônico}

O correio eletrônico é a base da maior parte da comunicação através do correio eletrônico qualquer usuário pode receber (e enviar) correspondência em seu E-mail (endereço eletrônico) em questão de minutos, qualquer parte do mundo. Para isto é necessário ter o E-mail individual e o do destinatário. Ter um E-mail é o primeiro passo para usar os outros recursos da internet.

\section{Grupos de discussão}

Um meio bastante popular de interagir com profissionais da mesma área de interesse ou mesmo com pessoas que compartilham dos problemas que estamos investigamos em uma área clínica é através dos fóruns ou grupos de discussões. Os interessados se inscrevem nas listas de interesse ou Listservs e recebem todas as mensagens enviadas pelos membros das listas. Na área da saúde em geral, ou enfermagem em particular, são inúmeros os grupos existentes agrupados por áreas de especialidades.Estas redes também podem ser usadas para coletar dados para pesquisas ou para discutir e comparar os resultados com especialistas de diferentes instituições. Apresentamos abaixo alguns endereços de Listservs e a mensagem que deve ser enviada para se inscrever nas listas:

* Professor Doutor do Departamento de Enfermagem Geral e Especializada da Escola de Ribeirão Preto da Universidade de São Paulo - Centro Colaborador da Organização Mundial da Saúde para o desenvolvimento da pesquisa em enfermagem 


\begin{tabular}{|c|c|c|c|}
\hline Lista & Área de discussão & E-mail & Para inscrever-se: \\
\hline ENFNET-1 & $\begin{array}{l}\text { É uma lista de discussão para } \\
\text { assuntos gerais na área de } \\
\text { enfermagem no Brasil }\end{array}$ & Listproc@mbox1.ufsc.br & $\begin{array}{llr}\text { Enviar a mensagem: } \\
\text { subscribe } & \text { ENFNET-1 seu } \\
\text { nome seguido do } & \text { do } \\
\text { sobrenome } & \end{array}$ \\
\hline NURSENET & $\begin{array}{l}\text { É um grupo de discussão de } \\
\text { questões globais de enfermagem } \\
\text { no mundo }\end{array}$ & Listserv@vm.utcc.utoronto & $\begin{array}{l}\text { Enviar a mensagem: } \\
\text { subscribe nursenet seu } \\
\text { nome seguido do } \\
\text { sobrenome }\end{array}$ \\
\hline CARENETL & $\begin{array}{l}\text { É uma lista de discussão para } \\
\text { docentes de enfermagem }\end{array}$ & carenetl@humber.bitnet & $\begin{array}{llr}\text { Enviar a mensagem: } \\
\text { subscribe } & \text { CRENETL seu } \\
\text { nome seguido do } & \text { dobrenome }\end{array}$ \\
\hline CNS-L & $\begin{array}{l}\text { É uma lista de discussão sobre } \\
\text { questões da prática clínica de } \\
\text { enfermegem }\end{array}$ & listserv@lisserv.utoronto.ca & $\begin{array}{l}\text { Enviar a mensagem: sub } \\
\text { CNS-L seu nome seguido } \\
\text { do sobrenome }\end{array}$ \\
\hline $\begin{array}{l}\text { CULTURE\& } \\
\text { nursing }\end{array}$ & $\begin{array}{l}\text { É UMA LISTA DA Escola de } \\
\text { Enfermagem da Universidade da } \\
\text { Califórnia em São Francisco que } \\
\text { discute os aspectos sócio- } \\
\text { econômicos da saúde }\end{array}$ & majordomo@itsserv1.ucsf.edu & $\begin{array}{l}\text { Enviar a mensagem: } \\
\text { subscribe culture-and- } \\
\text { nursing seguido do seu E- } \\
\text { mail }\end{array}$ \\
\hline GERINET & $\begin{array}{l}\text { É uma lista de discussão para } \\
\text { profissionais da área de geriatria }\end{array}$ & listserv@ubvm.bitnet & $\begin{array}{lrr}\text { Enviar a mensagem: } \\
\text { subscribe GERINET seu } \\
\text { nome seguido do } \\
\text { sobrenome }\end{array}$ \\
\hline
\end{tabular}

\section{Telnet}

Este recurso permite o acesso a outros sistemas dentro da Internet. Alguns requerem que tenhamos uma "conta' com uma identificação e senha, outros permitem um acesso temporário para que o usuário se familiarize com os serviços oferecidos e depois faça uma assinatura. Uma vez o acesso seja permitido, podemos usar todas as informações disponíveis como banco de dados, arquivos etc. $\mathrm{Na}$ área de enfermagem um recurso disponível por assinatura de grande utilidade pra pesquisadores é a Biblioteca Internacional der Enfermagem Virginia Henderson - mantida pela Sigma Theta Tau Internacional Honor Society. Ela contém programações de sessões científicas de organizações profissionais e banco de dados referentes a pesquisas e pesquisadores do mundo todo. É necessário inscrever-se embora os interessados possam entrar no sistema para conhecer. O endereço é: telnet stti-sun.iupui.edu e o login e senha é visitor.

Também a National Library of Medicine permite o acesso ao seu banco de dados composto de livros, catálogos, periódicos e audiovisuais. O endereço do telnet é: LOCATOR.NLM.NIH.GOV e a senha para entrar (login) é LOCATOR.

\section{World Wide Web ( WWW )}

É o componente mais usado hoje dentro da Internet que permite acessar informações em forma de textos, imagens e sons podendo ser usada como importante instrumento para facilitar pesquisas através dos serviços de busca. Em uma pesquisa realizada tendo câncer como palavra chave usando o serviço YAHOO! (www.yahoo.com) encontramos 533 páginas diferentes com referências ao assunto. O conteúdo abrangeu dentre outros: instituições que 
dão assistência de prevenção à reabilitação, páginas pessoais de pacientes, profissionais, sociedades médicas e de enfermagem e grupos de suporte e grande número de informações dirigidas a pacientes, familiares e cuidadores informais. Os sobreviventes da doença respondem por grande número de páginas localizadas sobre o assunto seja na divulgação de produtos desenvolvidos como obras de arte e literatura comum novo mercado de consumo para moda, acessórios, cosméticos. No serviço de catalogação brasileira, a consulta no YAIH? (http://www.ci.rnp.br/si/) encontrou apenas 44 registros, a maioria referente a instituições de ensino e assistência e paginas de especialistas.

\section{CONSIDERAÇÕES FINAIS}

Uma importante característica da Internet é o seu dinamismo onde novos dados são colocados como disponíveis a cada minuto. Esta característica, no entanto também é um dos pontos mais fracos da rede como fonte de pesquisa onde a fidedignidade das informações vai depender da análise da fonte dos dado já que todos podemos ter a nossa home page e divulgar o que quisermos. Contudo, a Internet é uma realidade que podem mudar a nossa maneiram de ver o mundo e para isso é necessário uma mente aberta, interativa e participativa para compreender e usar as novas tecnologias na busca de informações relevantes estimuladas pela nossa curiosidade e então adaptadas, contextualizadas e transformadas em conhecimento.

E-mail da autora: $\underline{\text { mhcaliri@glete.eerp.usp.br }}$ 